\section{Synthesis, Characterizations, and Properties of a P3HT- Hemin Covalent System for Solar Energy Conversions}

\section{Abstract}

Organic solar cells based on conjugated materials have widely been studied as potential renewable and low-cost alternatives for future solar energy conversions. The power conversion efficiency (PCE) of the best organic solar cells-bulk heterojunction (BHJ) cell reached to about $10 \%$. However, there is room for improvements. In this study, we intend to address the critical "photon loss" problem and the germinate charge carriers recombination problem via an energy level matched dye molecular units sensitized polymer approach, i.e., a "three-component" approach. Specifically, a covalent P3HT-Hemin system was synthesized and characterized successfully via esterification between $\mathrm{HO} / \mathrm{HO}$ P3HT and Hemin. The optoelectronic performance of P3HT-Hemin/PCBM cell is improved over the corresponding simple blend system, and this can be attributed to both improved photon capture and reduced charge recombination.

Keywords: Conjugated polymers; Molecular dyes; Lightharvesting; Optoelectronics; Photovoltaics; Solar cells; Energy conversions

\section{Sam-Shajing Sun ${ }^{1}$ and Dan Wang ${ }^{2}$}

1 Chemistry Department, Norfolk State University, 700 Park Avenue, Norfolk, VA, USA

2 Center for Materials Research, Norfolk State University, 700 Park Avenue, Norfolk, VA, USA

Corresponding author: Sun SS

" ssun@nsu.edu

Chemistry Department, Norfolk State University, 700 Park Avenue, Norfolk, VA, USA.

Tel: +1-757-823-2993

Fax: $+1-757-823-9054$

Citation: Sun SS, Wang D. Synthesis, Characterizations, and Properties of a P3HTHemin Covalent System for Solar Energy Conversions. Polym Sci. 2016, 2:1.

Organic solar cells based on donor/acceptor (D/A) conjugated molecular bulk-heterojunction (BHJ) blend system have achieved a best photoelectric power conversion efficiencies (PCEs) of about $10 \%$ [1,2]. Among those BHJ systems, regio-regular poly-(3hexylthiophene) (P3HT) is a conjugated polymer exhibiting one of the best values for polymer charge-carrier mobility, producing about $5 \%$ power conversion efficiency and an incident photon-tocurrent conversion efficiency (IPCE) of over $70 \%$ with [6,6]-phenyl$\mathrm{C}_{61}$-butyric acid methyl ester (PCBM) under one Sun intensity and 1.5 AM solar radiation, which can be used as a reference solar cell. Some principle explanations for the unique characteristics of $\mathrm{P} 3 \mathrm{HT}$, in comparison to other polymers, are high degree of solid state crystallinity, excellent charge mobility, extended absorption in the red region, and good chemical stability [3-5].

To develop high efficiency polymer photoelectric conversion systems, as elaborated earlier, among the five organic photovoltaic transformation steps and the three major losses, it was believed that the "photon loss" in the first sunlight harvesting step and the carrier loss in the carrier transport step are the bottle neck steps. In this study, we intent to address the critical "photon loss" problems and the germinate charge carrier recombination problem via an energy level matched dye molecular units sensitized "three-component" polymer approach. This "threecomponent" system can further minimize the photon loss via better energy matched and high light absorption coefficient dye molecular units, and also simultaneously minimize the photo generated opposite charge pair recombination via further separation of photo generated opposite charges into the donor and the acceptor moieties apart from the dyes similar like in a natural photosynthetic process.

Regio-regular poly-(3-hexylthiophene) (P3HT) and a serious of derivatives with subsequent end-group functionalization of the polymers have been studied by McCullough and his co-workers [6-10]. In the past ten years, many other researchers have developed the method to synthesize a serious of polythiophene derivatives and polythiophene diblock copolymers [11-13]. In order to capture more photon and prevent charge carriers from recombination, Hemin molecule was desirably to be attached covalently to the $\mathrm{P} 3 \mathrm{HT}$ chains, and the (di) hydryoxyl-terminated P3HT (HO/HOP3HT) was synthesized using Grignard metathesis (GRIM) polymerization, which was reported in the literature $[7,14]$.

In this study, commercial Hemin with two - $\mathrm{COOH}$ groups provides convenient conditions of esterification with $-\mathrm{OH}$ group terminated $\mathrm{P} 3 \mathrm{HT}$, while the reaction of $-\mathrm{COOH}$ with $-\mathrm{OH}$ 
is not a spontaneous reaction in mild conditions and at room temperature. To enhance the reactivity of the alcohol group to the protoporphyrin, Sami Boufi used carbonyldiimidazole (CDI) as an activator and 1,8-diaminooctane and 1,4-phenylenediamine as spacer to overcome molecular hindrance problem [15], but the synthesis procedure was complicated. As one way to circumvent this problem, the Steglich esterification method, which was first described by Wolfgang Steglich in in 1978 is a different process of dicyclohexylcarbodiimide as a coupling reagent and 4-dimethylaminopyridine as a catalyst [16]. Steglich esterification was accepted in this study due to the mild reaction condition and high conversion because of the favorable catalytic action of dimethyl aminopyridine.

Hemin contains a porphyrin ring with a ferric iron ion and a chloride ligand. Although the NMR spectra of synthetic and natural porphyrin complexes of high-spin and low-spin have been investigated, $[16,17]$ Characterization of Hemin by NMR is still difficult in our case due to Hemin's poor solubility and molecular aggregation in solution. The good solvents for Hemin include DMSO, DMF, 5\% aqueous sodium dodecyl sulfate, $[16,17]$ etc., but polymer P3HT is insoluble in those solvent. On the other hand, because iron (III) is paramagnetic material, the porphyrin proton resonances are shifted due to the metal element, generally outside the normal diamagnetic region [17]. Because of the discussions above, NMR was not utilized in characterization of Hemin and monitoring esterification between hydroxyl-terminated $\mathrm{P} 3 \mathrm{HT}$ and Hemin, alternative methods shall be utilized.

\section{Experimental Section}

\section{Materials}

2,5-Dibromo-3-hexylthiophene, isopropylmagnesium chloride solution in THF, [1,3-Bis(diphenylphosphino) propane] dichloronickel(II)(Ni(dppp)Cl2), Phosphorus oxychloride (POCl3), Dicyclohexylcarbodiimide(DCC), 4-(Dimethylamino)pyridine (DMAP), anhydrous Tetrahydrofuran(THF) were purchased from Sigma-Aldrich without further purification. [6,6]-Phenyl C61 butyric acid methyl ester (PCBM) was used as received from Nano-C. N-Methylformanilide was purchased from Acros. Chloroprotoporphyrin IX iron(III) (Hemin) and Lithium aluminum hydride(LiAlH4) were purchased form Pfaltz and Bauer and used as received. Poly (3,4-ethylenedioxythiophene) (PEDOT):poly(styrene sulfonate) (PSS) (Clevios P VP Al 4083) was purchased from H. C. Stark and passed through a $0.25 \mu \mathrm{m}$ filter before spin-coating.

\section{Characterization}

${ }^{1} \mathrm{H}$ NMR spectrums were obtained by a Bruker Advance $300 \mathrm{MHz}$ spectrometer, and all NMR samples were dissolved in $\mathrm{CDCl} 3$, unless otherwise stated. Molecular weights of polymer samples were measured on a Viscotek Gel permeation Chromatography (GPC) system with a UV-VIS absorption detector at room temperature, and standard polystyrene (PS) was used as conventional calibration. Photoluminescence measurements were performed on an ISA Flouromax-3 luminescence spectrofluorometer THF as solvent. UV-VIS spectrometer was obtained absorption maximum peak wavelength $\left(\lambda_{\text {max }}\right)$ and optical energy gap ( $\left.E_{g}{ }^{o p t}\right)$ of these polymers in THF solutions (PerkinElmer Lamba-1050 UV-VIS-NIR spectrometer). The current-voltage curves of the cells produced were measured under an AM $1.5 \mathrm{G}$ solar simulator with $100 \mathrm{~mW} /$ $\mathrm{cm}^{2}$ intensity. The active areas of the cells were $0.2025 \mathrm{~cm}^{2}$.

\section{Fabrication of solar cell devices}

For comparison studies, $11.55 \mathrm{mg}$ P3HT-Hemin and $10 \mathrm{mg}$ PCBM, $10 \mathrm{mg}$ P3HT and $10 \mathrm{mg}$ PCBM were dissolved in $1 \mathrm{~mL}$ 1,2-Dichlorobenzene (DCB) respectively, and the mixture solutions were stirred at room temperature for $24 \mathrm{hrs} .10 \mathrm{mg}$ P3HT, $0.155 \mathrm{mg} \mathrm{Hemin}$ and $10 \mathrm{mg}$ PCBM were dissolved in $1 \mathrm{~mL}$ mixture solvent of DCB and DMF $(3: 1, \mathrm{v} / \mathrm{v})$.

The ITO glass $\left(R_{s}=8-12 \Omega\right)$ was cleaned by sequential 5 mins sonication in solutions of detergent, acetone, isopropyl alcohol and deionized water. The cleaned ITO glass was treated 15 mins UV-ozone to improve the wettability of PEDOT:PSS. Spin coat PEDOT:PSS aqueous solution (Clevious P VP Al 4083, from H.C. Starck) onto clean ITO glasses in $5000 \mathrm{rpm}$ for $30 \mathrm{~s}$ forming 30 $\mathrm{nm}$ thin film in thickness, followed by drying in vacuum oven at $90^{\circ} \mathrm{C}$ for 1 hour to further get rid of the water in the PEDOT:PSS thin film. After cooling down to room temperature, the polymer mixture solution was spun on the top of dried "ITO/PDOT:PSS" film in $1000 \mathrm{rpm}$ for $60 \mathrm{~s}$, and when dried the polymer films by putting them in a high vacuum oven at $80^{\circ} \mathrm{C}$ for 30 mins. All solution samples were through $0.2 \mu \mathrm{m}$ filter before spin coating. After cooling down to room temperature, evaporation of metal Al was performed in a glove box device with the pressure as low as $1-2 \times 10^{7} \mathrm{mbar}$ till the film thickness of $100 \mathrm{~nm}$.

\section{Synthetic Schemes and Procedures}

Synthetic scheme for hydroxyl terminated P3HT and P3HT-Hemin are given in Schemes $\mathbf{1}$ and $\mathbf{2}$

\section{H/H Group Terminated Poly(3- hexylthiophene)}

2,5-Dibromo-3-hexylthiophene (2.273 g, $6.96 \mathrm{mmol}, 1$ equiv.) was dissolved in anhydrous THF $(50 \mathrm{~mL})$ in a dry $100 \mathrm{~mL}$ threeneck flask under Argon. $2 \mathrm{M}$ isopropylmagnesium chloride solution ( $3.48 \mathrm{~mL}, 6.96 \mathrm{mmol}, 1$ equiv.) in THF was added via a syringe, and the mixture was refluxed for $2 \mathrm{~h}$. After cooling down

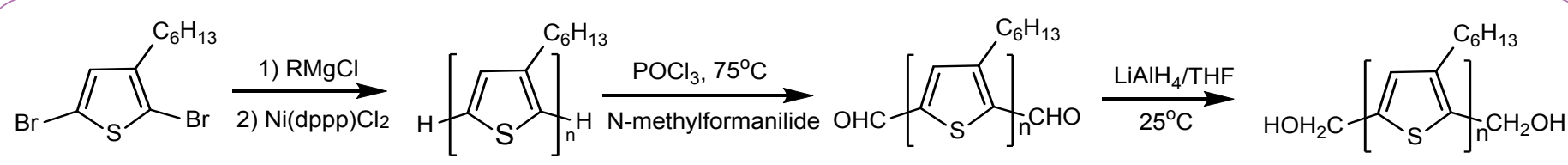




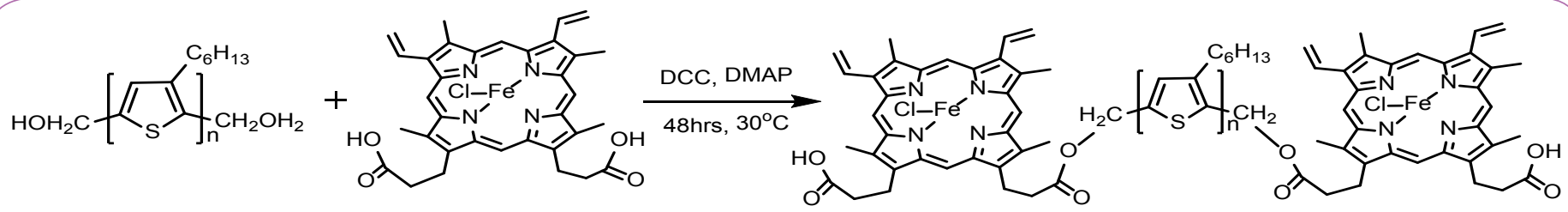

$\mathrm{HO} / \mathrm{HO}-\mathrm{P} 3 \mathrm{HT}$

P3HT-Hemin

Scheme 2 Synthetic scheme for the P3HT-Hemin.

to room temperature, $\mathrm{Ni}(\mathrm{dppp}) \mathrm{Cl}_{2}(0.15 \mathrm{~g}, 0.27 \mathrm{mmol}, 0.039$ equiv.) was added to the flask. The reaction mixture was stirred at room temperature for 30 mins followed by the addition of 2 $\mathrm{M}$ isopropylmagnesium chloride solution $(0.5 \mathrm{~mL}, 1 \mathrm{mmol}, 0.14$ equiv.) in THF. The reaction mixture was stirred at $70^{\circ} \mathrm{C}$ for $15 \mathrm{mins}$ followed by adding $2 \mathrm{M} \mathrm{HCl}$ solution. Methanol was added after mixture cooling down room temperature, and brown precipitate polymer formed. The brown product was purified by sequential Soxhlet extractions with methanol, hexanes, and chloroform to

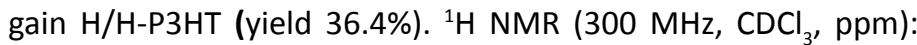
$\delta=6.98(\mathrm{~s}, 49 \mathrm{H}), 2.81(\mathrm{t}, \mathrm{J}=8.0 \mathrm{~Hz}, 98 \mathrm{H}), 1.71(\mathrm{~m}, 98 \mathrm{H}), 1.50-1.25$ $(\mathrm{m}, 294 \mathrm{H}), 0.91$ (t, J=7.0 Hz, 147H); GPC: $M n=8430, \mathrm{PDI}=1.15$.

\section{OHC/OHC Group Terminated Poly(3- hexylthiophene) (OHC/OHC-P3HT)}

$\mathrm{H} / \mathrm{H}-\mathrm{P} 3 \mathrm{HT}(0.2 \mathrm{~g}$ ) was dissolved in $50 \mathrm{~mL}$ anhydrous toluene in a dry flask under Argon. $\mathrm{N}$-methylformanilide $(2 \mathrm{~mL}, 18.4 \mathrm{mmol}$ ) and $\mathrm{POCl}_{3}(1.4 \mathrm{~mL}, 15.1 \mathrm{mmol})$ were then added to the solution, and the reaction was stirred at $75^{\circ} \mathrm{C}$ for $24 \mathrm{hrs}$. After cooling to room temperature, saturated aqueous solution of sodium acetate was added and kept stirring for another $2 \mathrm{hrs}$, at which time methanol was added to reaction mixture to precipitate brown product. The polymer was purified by sequential Soxhlet extractions with methanol, hexanes, and chloroform. After removing chloroform in a vacuum, $0.195 \mathrm{~g}$ (yield 97.5\%) of OHC/OHC-P3HT was obtained. ${ }^{1} \mathrm{H}$ NMR (300 MHz, $\left.\mathrm{CDCl}_{3}, \mathrm{ppm}\right): \delta=10.02$ and 9.99 (2H totally), $6.98(\mathrm{~s}, 49 \mathrm{H}), 2.81(\mathrm{t}, \mathrm{J}=8.0 \mathrm{~Hz}, 98 \mathrm{H}), 1.71(\mathrm{~m}, 98 \mathrm{H}), 1.50-1.25(\mathrm{~m}$, 294H), 0.91 (t, J=7.0 Hz, 147H); GPC: $M n=8400, P D I=1.15$.

\section{$\mathrm{CH} 2 \mathrm{OH} / \mathrm{CH} 2 \mathrm{OH}$ Group Terminated Poly(3-hexylthiophene) (HO/HO-P3HT)}

A $100 \mathrm{~mL}$ three-neck flask was charged with OHC/OHC-P3HT $(0.158 \mathrm{~g})$ and anhydrous THF $(40 \mathrm{~mL})$ under argon, followed by addition of $\mathrm{LiAlH}_{4}$ solution in THF (1 M, $\left.1.2 \mathrm{~mL}\right)$ via a syringe. The mixture solution was stirred at room temperature for $1 \mathrm{~h}$, at which time $\mathrm{HCl}(1 \mathrm{M}, 2 \mathrm{~mL})$ was added. The crude was precipitated in methanol and purified by sequential Soxhlet extraction with methanol, hexanes and chloroform to gain $0.15 \mathrm{~g}$ (yield 95\%) HO/ HO-P3HT. ${ }^{1} \mathrm{H}$ NMR (300 MHz, CDCl $\left.{ }_{3}, \mathrm{ppm}\right): \delta=6.98(\mathrm{~s}, 49 \mathrm{H}), 4.75(\mathrm{~s}$, $4 \mathrm{H}), 2.81(\mathrm{t}, \mathrm{J}=8.0 \mathrm{~Hz}, 98 \mathrm{H}), 1.71(\mathrm{~m}, 98 \mathrm{H}), 1.50-1.25(\mathrm{~m}, 294 \mathrm{H})$, $0.91(\mathrm{t}, \mathrm{J}=7.0 \mathrm{~Hz}, 147 \mathrm{H})$; GPC: $\mathrm{Mn}=8400, \mathrm{PDI}=1.15$.

\section{Poly(3-Hexylthiophene)-Hemin (P3HT- Hemin)}

In a $250 \mathrm{~mL}$ round-bottom flask, HO/HO-P3HT (50 mg, Mn=8400, $\mathrm{Mw} / \mathrm{Mn}=1.15$ by $\mathrm{GPC}$ ) and Hemin $(65.2 \mathrm{mg}, 0.1 \mathrm{mmol})$ were dissolved in anhydrous THF (160 ml) under Argon at $65^{\circ} \mathrm{C}$ and the reaction mixture was stirred for $1 \mathrm{~h}$. After cooling down to room temperature, 4-Dimethylaminopyridine (DMAP, $3.66 \mathrm{mg}$, $0.03 \mathrm{mmol}$ ) were added to the reaction mixture. The mixture was kept stirring at room temperature for 30 mins, followed by the adding of 1,3-dicyclohexylcarbodiimide (DCC, $30.9 \mathrm{mg}, 0.15$ $\mathrm{mmol})$ dissolved in anhydrous $\operatorname{THF}(10 \mathrm{~mL})$, which was added dropwise using a syringe. The mixture was stirred at $40^{\circ} \mathrm{C}$ for 48 hrs. Brown precipitate polymer formed in methanol and purified by sequential Soxhlet extractions with methanol, hexanes. The polymer was isolated from the chloroform solution and dried under vacuum to give $48 \mathrm{mg}$ (yield $=83 \%$ ) of desired product P3HT-Hemin. GPC: $M n=9600$, PDI=1.15.

\section{Results and Discussion}

The synthetic routes for preparation of HO/HO-P3HT and P3HTHemin were shown in Schemes 1 and 2. The covalent P3HTHemin was prepared in four steps: (1) Synthesis of $\mathrm{H} / \mathrm{H}-\mathrm{P} 3 \mathrm{HT},(2)$ Synthesis of OHC/OHC-P3HT, (3) Synthesis of HO/HO-P3HT and (4) synthesis of P3HT-Hemin. By following the procedure reported in the literature $[7,14]$, two sided hydroxypropyl-terminated $\mathrm{P} 3 \mathrm{HT}$ (HO/HO-P3HT) was synthesized first, and then reacted with Hemin using the Steglich esterification, which preferred for its convenience and effectiveness. The reaction condition was mild, yet the conversion was high because of the favorable catalytic action of dimethylaminopyridine [16-19]. The formation of $\mathrm{H} / \mathrm{H}$ P3HT was identified by ${ }^{1} \mathrm{H}$ NMR (Figure 1). Two $\delta$ - $\mathrm{CHO}$ peaks of different intensity could be found from ${ }^{1} \mathrm{H}$ NMR spectrum of $\mathrm{OHC} /$ OHC-P3HT (Figure 2). The peak at $\delta 10.02$ with highly dominant should be from the proton of - $\mathrm{CHO}$ at the 2-position end, and the other small peak at $\delta 9.99$ was presumably assigned to the $-\mathrm{CHO}$ at the 5-position end. The NMR data of those two peaks indicated that 2-position chain ends had much higher abundance than 5 -position ends in the product. The ${ }^{1} \mathrm{H}$ NMR integration indicated the polymer having 48 repeat units.

Figure 3 indicated that the OHC/OHC-P3HT was reduced by $\mathrm{LiAlH}_{4}$ to HO/HO-P3HT. ${ }^{1} \mathrm{H}$ NMR spectra had confirmed the accomplishment of the reduction. The $\delta \mathrm{CHO}$ peaks at 10.2 disappeared, and a new doublet peak at $\delta 4.75$ was absorbed which belonged to the $-\mathrm{CH}_{2} \mathrm{OH}$ [7] (Figure 3).

In this study, P3HT synthesized with a narrow molecular weight distribution ( $\mathrm{Mw} / \mathrm{Mn}=1.15)$ and reasonable molecular weight ( $M n=8430$, repeat unit $=49$ ) for solar cells application was obtained via precise controlling amount of $\mathrm{Ni}(\mathrm{dppp}) \mathrm{Cl}_{2}$. The molecular weight difference between P3HT-Hemin and P3HT was 1200 Daltons, which was about the molecular weight summation of two Hemin molecules, indicating that P3HT chain was terminated 


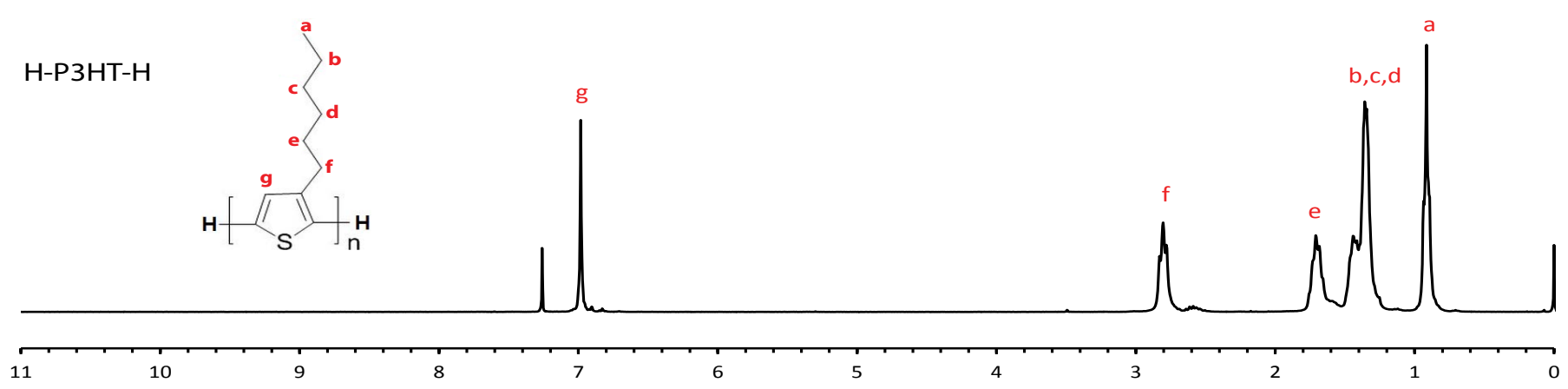

Figure $1{ }^{1} \mathrm{H}$ NMR spectrum of hydrogen terminated P3HT.
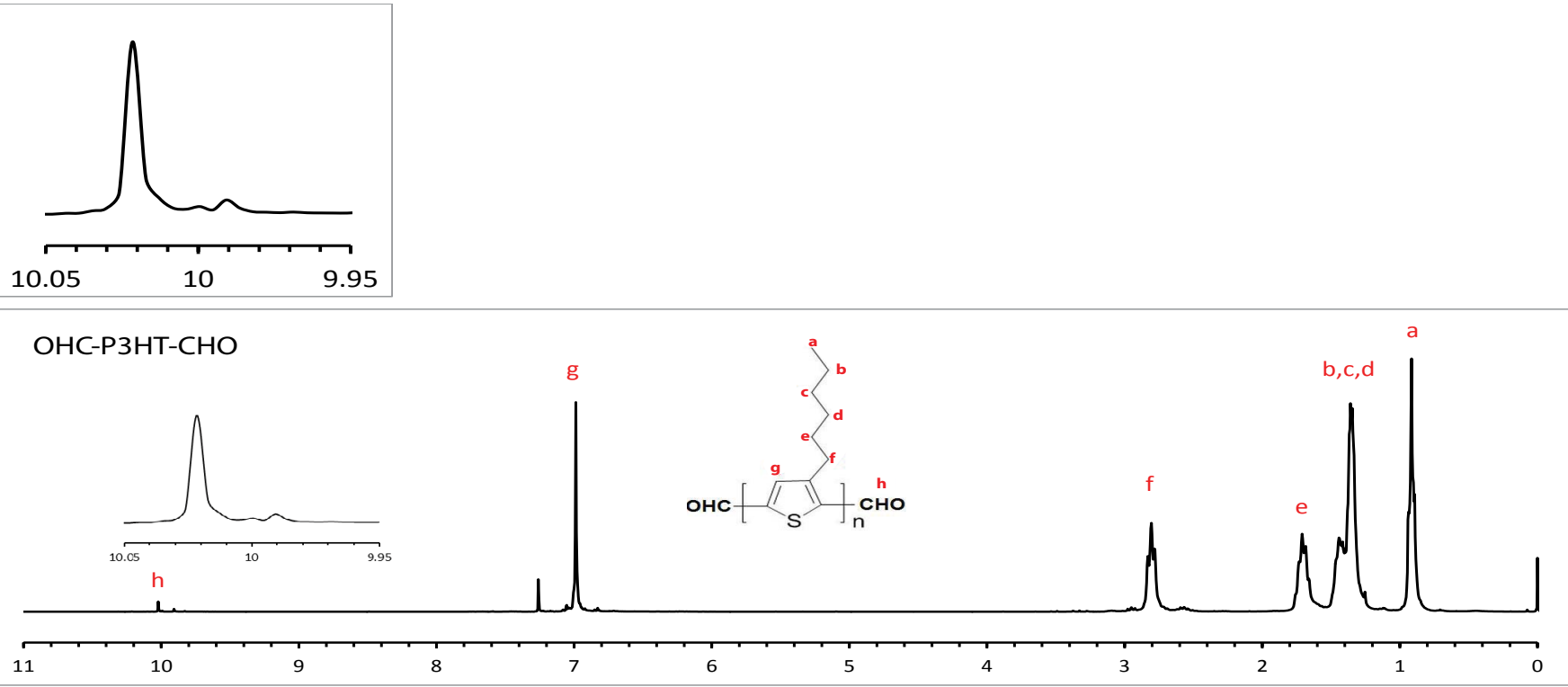

Figure $2{ }^{1} \mathrm{H}$ NMR spectrum of $\mathrm{CHO} / \mathrm{CHO}$ group terminated $\mathrm{P} 3 \mathrm{HT}$.
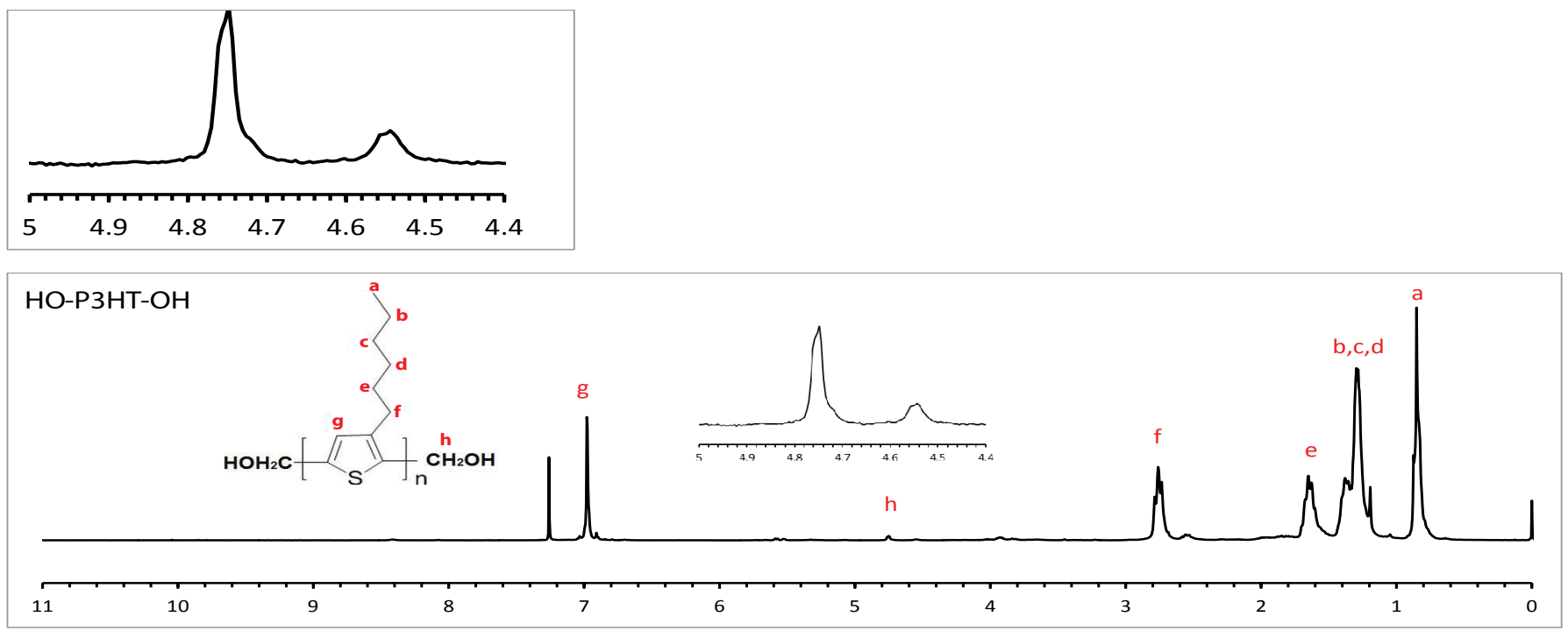

Figure $3{ }^{1} \mathrm{H}$ NMR spectrum of $\mathrm{OH} / \mathrm{OH}$ group terminated $\mathrm{P} 3 \mathrm{HT}$. 
by two Hemin molecules. The repeat unit number of 49 obtained via gel permeation chromatography (GPC) (Table 1 ) very closed to 48 repeat units in ${ }^{1} \mathrm{H}$ NMR (Figure 1). P3HT-Hemin molecules with one response peak had short elution time comparing to $\mathrm{P} 3 \mathrm{HT} /$ Hemin bland with two response peaks, which also testified that $\mathrm{P} 3 \mathrm{HT}$-Hemin was not simply physical mixture of P3HT/Hemin. (Figure 4)

Figure 5 showed the UV-visible absorption spectra of $\mathrm{P} 3 \mathrm{HT}$, Hemin, P3HT-Hemin and P3HT/Hemin bland in THF solution. The maximum absorption wavelength $\left(\lambda_{\max }\right)$ of $\mathrm{P} 3 \mathrm{HT}$-Hemin at $419 \mathrm{~nm}$ was blue shifted comparing to pure $\mathrm{P} 3 \mathrm{HT}$ molecules with $\lambda_{\max }$ at $445 \mathrm{~nm}$, and also was different with the absorption spectra of $\mathrm{P} 3 \mathrm{HT} /$ Hemin blend and pure Hemin molecules, which implied that covalent P3HT-Hemin was synthesized successfully via the Steglich esterification.

The photoluminescence (PL) comparison of P3HT and P3HT-Hemin in THF solution was shown in Figure 6. P3HT and P3HT-Hemin samples with the same concentration $\left(1.0 \times 10^{-4} \mathrm{M}\right)$ were excited respectively using the same excitation wavelengthof $400 \mathrm{~nm}$. The photoluminescence of P3HT-Hemin solution exhibited dramatically quenching performance, and the maximum PL intensity was more than $58 \% \mathrm{PL}$ quenching compared to pure P3HT solution at $470 \mathrm{~nm}$ and $468 \mathrm{~nm}$, respectively. The PL quenching was because electrons transferred from $\mathrm{P} 3 \mathrm{HT}$ section as donor to Hemin section as acceptor in P3HT-Hemin molecules.

The performance of the fabricated solar cell devices was

Table 1: GPC parameters of HO-P3HT-OH and P3HT-Hemin.

\begin{tabular}{|c|c|c|}
\hline & HO-P3HT-OH & P3HT-Hemin \\
\hline $\mathrm{Mn}$ - (Daltons) & 8430 & 9638 \\
\hline $\mathrm{Mw}$ - (Daltons) & 9666 & 11012 \\
\hline $\mathrm{Mz}$ - (Daltons) & 10860 & 12345 \\
\hline $\mathrm{Mp}$ - (Daltons) & 9398 & 10663 \\
\hline
\end{tabular}

measured using an AM 1.5 G solar simulator with about one Sun intensity $\left(100 \mathrm{~mW} / \mathrm{cm}^{2}\right)$, where the device scheme are shown in Figure 7.

Figure 8 and Table 2 indicated that P3HT-Hemin/PCBM solar cell devices exhibited $63 \%$ enhancement of power conversion efficiency (PCE), 9.8\% enhancement of $\mathrm{J}_{\mathrm{sc}^{\prime}}$ and $28.6 \%$ enhancement of $\mathrm{V}_{\text {oc }}$ than the P3HT/Hemin/PCBM blend cells, and $16 \%$ enhancement of $\mathrm{V}_{\text {oc }}$ than P3HT/PCBM cells. Better photo induced charge separation appears to be the key factor in P3HT-Hemin/PCBM cells due to more convenient reach of photo generated excitons toward the P3HT-Dye interface.

\section{Conclusions}

The NMR, GPC, UV-vis, and PL quenching data provided evidences that P3HT-Hemin covalent system was synthesized successfully via esterification between $\mathrm{HO} / \mathrm{HO}-\mathrm{P} 3 \mathrm{HT}$ and Hemin. P3HTHemin/PCBM solar cell devices exhibited $63 \%$ enhancement of PCE and $9.8 \%$ enhancement of $J_{s c}$ than the P3HT/Hemin/PCBM blend cells, and $16 \%$ enhancement of $\mathrm{V}_{\text {oc }}$ than P3HT/PCBM cells. Better photo induced charge separation appears to be the key factor in P3HT-Hemin/PCBM cells due to more convenient reach of photo generated excitons toward the P3HT-Hemin interface. Further systematic optimizations involving better molecular dye units, and better polymer solid state morphologies are expected to further increase the overall device optoelectronic efficiencies.

\section{Acknowledgments}

This material is based upon work supported, in part, by project awards from the Department of Defense (award \#W911NF-11-1-0158 and \#W911NF-15-1-0422), the National Science Foundation (awards \#1036494 and DGE-0966188), and Department of Energy (award \# EE0004002).

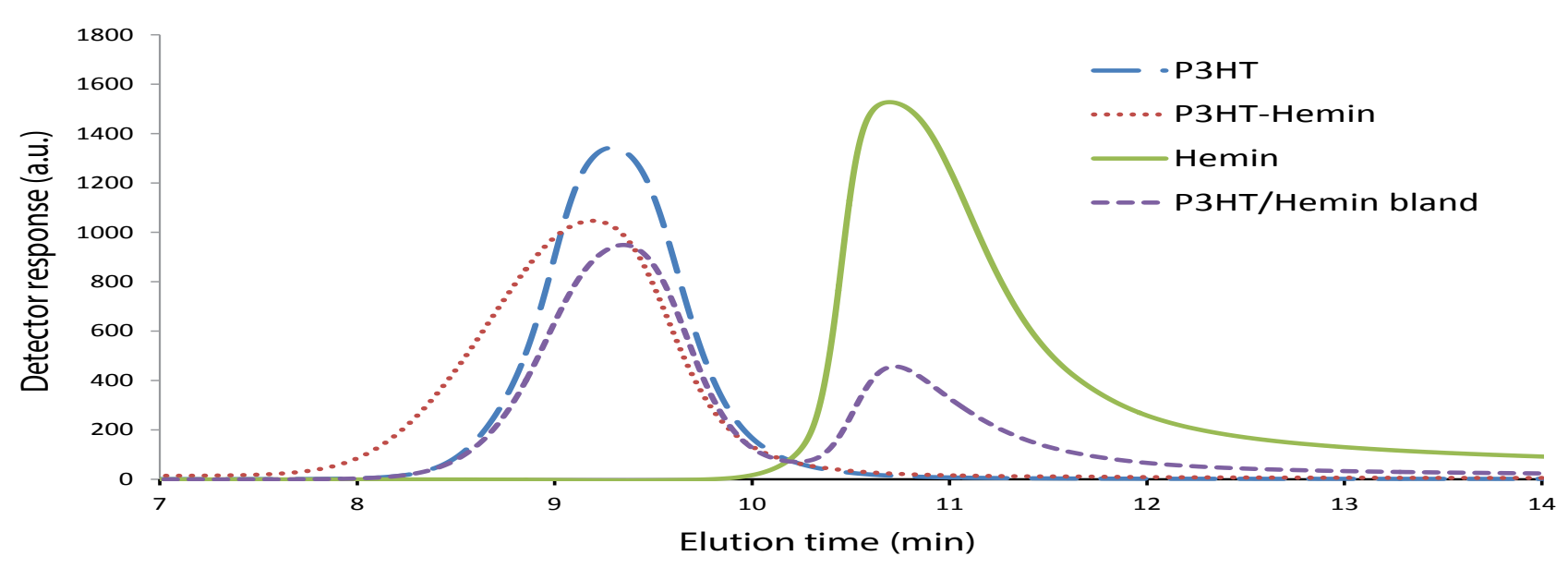

Figure 4 GPC traces of HO-P3HT-OH, Hemin, P3HT/Hemin blend and P3HT-Hemin covalent system. 


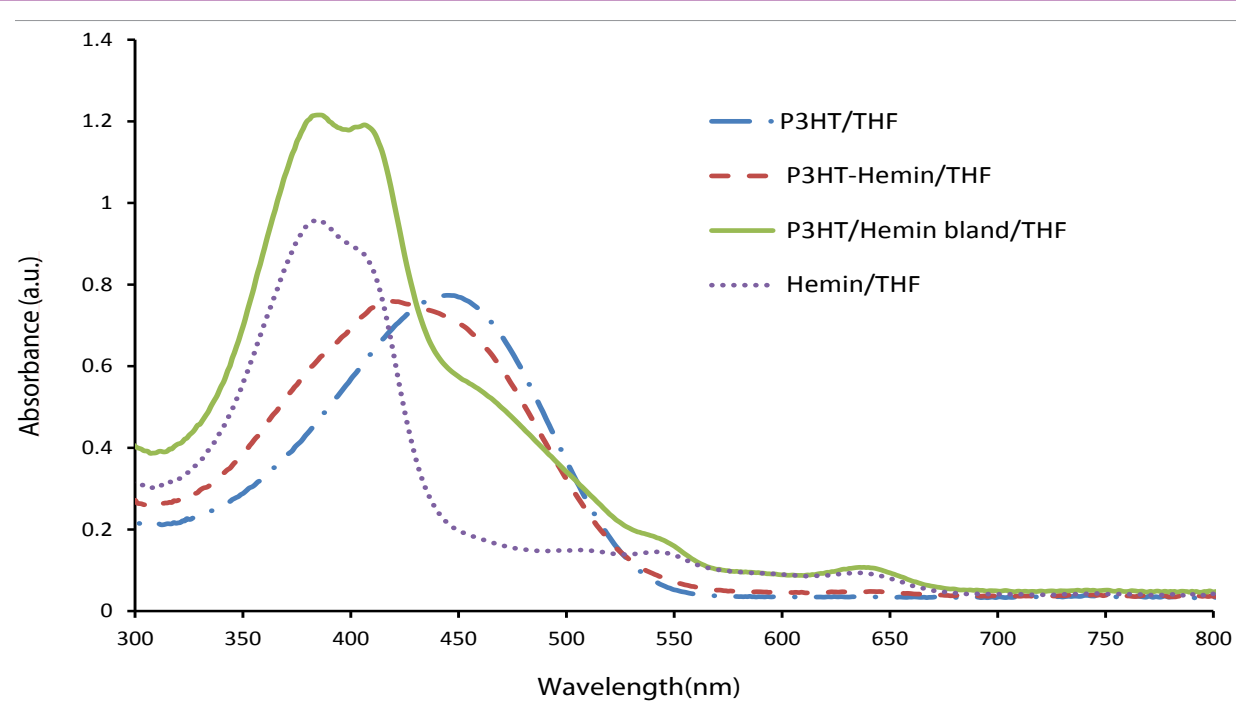

Figure 5 UV-visible absorption spectra of P3HT, Hemin, P3HT-Hemin covalent system and P3HT/Hemin blend in THF.

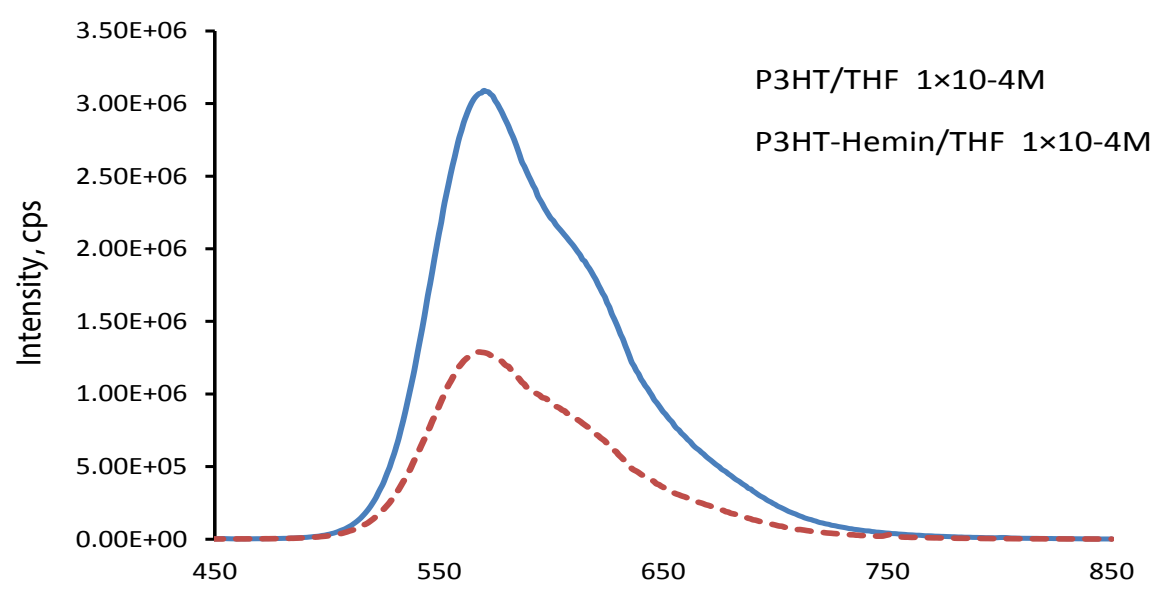

Figure 6 PL spectrum of P3HT and P3HT-Hemin, $1 \times 10^{-4} \mathrm{M}$.

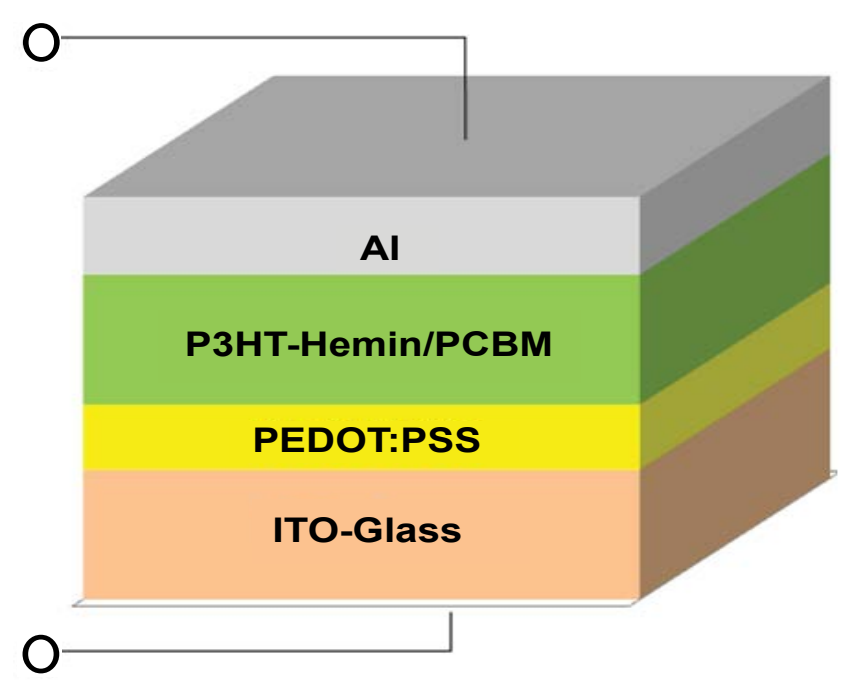

Figure 7 Schematic of device structure of P3HT-Hemin/PCBM. 


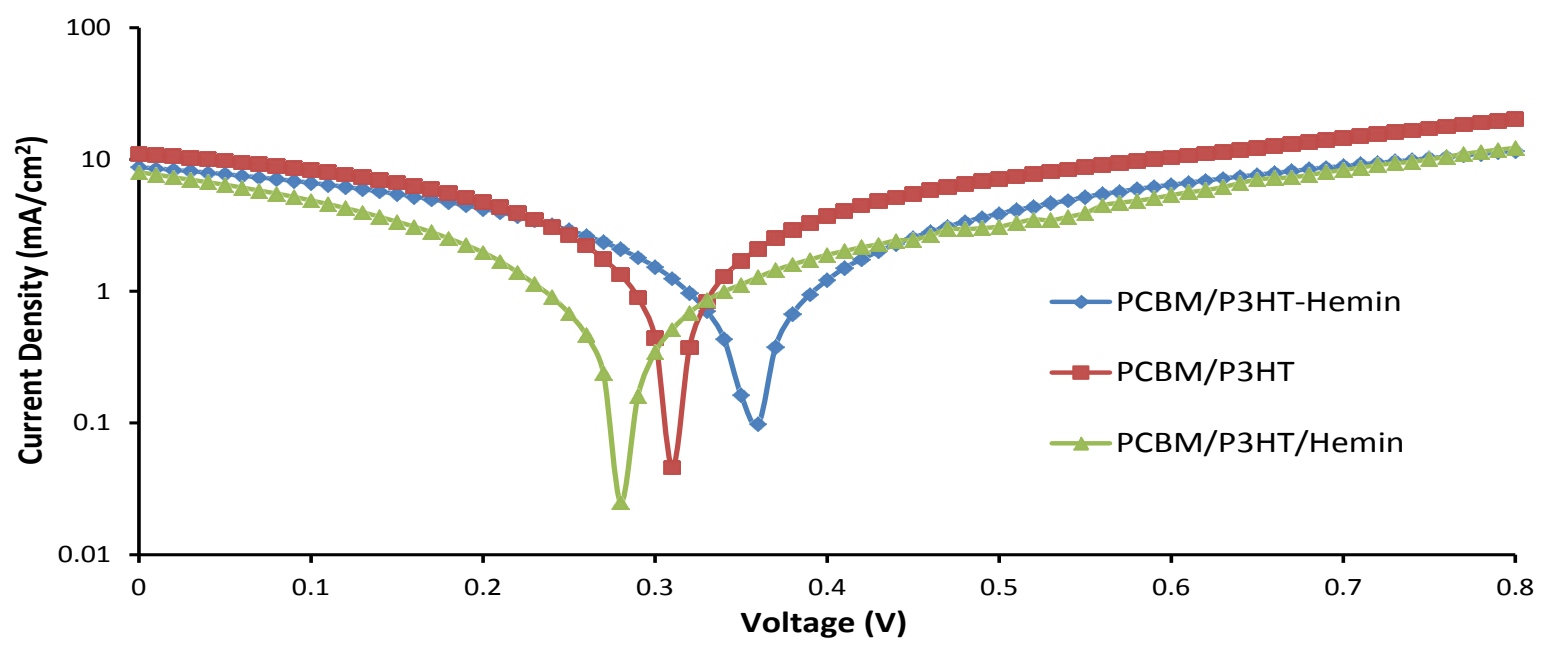

Figure 8 The J-V curves of P3HT/PCBM, P3HT-Hemin/PCBM and P3HT/Hemin/PCBM solar cells.

Table 2 The photovoltaic parameters of P3HT-Hemin/PCBM, P3HT/ $\mathrm{PCBM}$ and P3HT/PCBM/Hemin (Un-calibration).

\begin{tabular}{|c|c|c|c|}
\hline & $\begin{array}{c}\text { P3HT-Hemin/ } \\
\text { PCBM }\end{array}$ & P3HT/PCBM & $\begin{array}{c}\text { P3HT/PCBM/ } \\
\text { Hemin }\end{array}$ \\
\hline $\mathrm{J}_{\mathrm{sc}} \mathrm{mA} / \mathrm{cm}^{2}$ & 8.74 & 11.00 & 7.96 \\
\hline $\mathrm{Voc}, \mathrm{V}$ & 0.36 & 0.31 & 0.28 \\
\hline $\mathrm{FF}, \%$ & 27.14 & 29.61 & 23.17 \\
\hline $\mathrm{PCE}, \%$ & 0.86 & 1.02 & 0.53 \\
\hline
\end{tabular}




\section{References}

1 Dennler G, Scharber MC, Brabec CJ (2009) Polymer-Fullerene BulkHeterojunction Solar Cells. Adv Mater 21: 1323-1338.

2 Scharber MC, Muhlbacher D, Koppe M, Denk P, Waldauf C, et al. (2006) Design Rules for Donors in Bulk-Heterojunction Solar CellsTowards 10\% Energy-Conversion Efficiency. Adv Mater 18: 789-794.

3 Yu G, Gao J, Hummelen JC, Wudl F, Heeger AJ (1995) Polymer Photovoltaic Cells: Enhanced Efficiencies via a Network of Internal Donor-Acceptor Heterojunction. Science 270: 1789-1791.

4 Chen FC, Xu Q, Yang Y (2004) Enhanced efficiency of plastic photovoltaic devices by blending with ionic solid electrolytes. App Phys Lett 84: 3181-3183.

5 Li G, Shrotriya V, Yao Y, Yang Y (2005) Investigation of annealing effects and film thickness dependence of polymer solar cells based on poly(3-hexylthiophene). J Appl Phys 98: 043704.

6 Jeffries ELM, Sauve G, McCullough RD (2005) Facile synthesis of endfunctionalized regioregular poly(3-alkylthiophene)s via modified grignard metathesis reaction. Macromolecules 38: 10346-10352.

7 Liu J, McCullough RD (2002) End group modification of regioregular polythiophene through postpolymerization functionalization. Macromolecules 35: 9882-9889.

8 Jeffries ELM, Sauve G, McCullough RD (2004) In-situ end group functionalization of regionregular poly(3-alkylthiophene) using the grignard metathesis polymerization method. Adv Mater 16: 10171019.

9 Lovu MC, Jeffries ELM, Sheina EE, Cooper JR, McCullough RD (2005) Regioregular poly(3-alkylthiophene) conducting block copolymers. Polymer 46: 8582-8586.

10 Kim JS, Lee Y, Lee JH, Park JH, Kim JK, Cho K (2010) High-Efficiency Organic Solar Cells Based on End-Functional-Group-Modified Poly(3hexylthiophene). Adv Mater 22: 1355-1360.

11 Surin M, Coulembier O, Tran K (2010) Regioregular poly(3hexylthiophene)-poly(e-caprolactone) block copolymers: controlled synthesis, microscopic morphology, and charge transport properties. Org Electron 11: 767-774.

12 Lee JU, Cirpan A, Emrick T, Russell TP, Jo WH (2009) Synthesis and photophysical property of well-defined donor-acceptordiblock copolymer based on regioregular poly(3-hexylthiophene) and fullerene. J Mater Chem 19: 1483-1489.

13 Liu J, Sheina E, Kowalewski T, McCullough RD (2002) Tuning the electrical conductivity and self-assembly of regioregular polythiophene by block copolymerization: nanowire morphologies in new di- and triblock copolymers. Angew Chem Int Ed 41: 329-332.

14 Boufi S, Vilar MR, Parra V, Ferraria AM, Botelho do Rego AM (2008) Grafting of porphyrins on cellulose nanometric films. Langmuir 24: 7309-7315.

15 Neises B, Steglich W (1978) Simple Method for the Esterification of Carboxylic Acids. Angew Chem Int Ed 17: 522-524.

16 Walker FA, Benson M (1982) Models of the cytochromes b. 3. Prediction of the orientation of the in-plane heme symmetry axis in unsymmetrically substituted low-spin hemins from the temperature dependence of their proton isotropic shifts. J Phys Chem 86: 34953499.

17 Mazumdar S, Medhi OK, Mitra S (1988) Six-coordinated highspin models for ferric hemoproteins: NMR and ESR study of the diaquo(protoporphyrinato IX)iron(III) cation and aquohydroxo(protoporphyrinato IX)iron(III) intercalated in aqueous detergent micelles. Inorg Chem 27: 2541-2543.

18 Brockmann T, Tour JM (1995) Synthesis and properties of lowbandgap zwitterionic and planar conjugated pyrrole-derived polymeric sensors. reversible optical absorption maxima from the UV to the near-IR. J Am Chem Soc 117: 4437-4447.

19 Lee JU, Kim YD, Jo JW, Kim JP, Jo WH (2011) Efficiency enhancement of P3HT/PCBM bulk heterojunction solar cells by attaching zinc phthalocyanine to the chain-end of P3HT. J Mater Chem 21: 1720917218. 